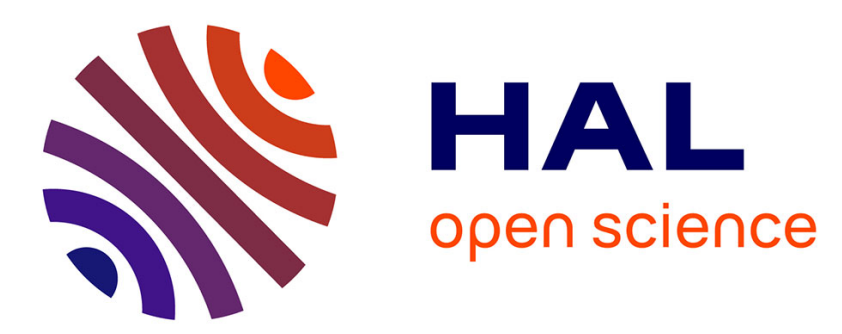

\title{
Ceramic panel heating under impinging methane-air premixed flame jets
}

Mohamed Jarray, K Chetehouna, Nicolas Gascoin, Fatimah Bey

\section{To cite this version:}

Mohamed Jarray, K Chetehouna, Nicolas Gascoin, Fatimah Bey. Ceramic panel heating under impinging methane-air premixed flame jets. International Journal of Thermal Sciences, 2016, 107, pp.184-195. 10.1016/j.ijthermalsci.2016.04.014 . hal-01312657

\section{HAL Id: hal-01312657 https://hal.science/hal-01312657}

Submitted on 14 May 2016

HAL is a multi-disciplinary open access archive for the deposit and dissemination of scientific research documents, whether they are published or not. The documents may come from teaching and research institutions in France or abroad, or from public or private research centers.
L'archive ouverte pluridisciplinaire HAL, est destinée au dépôt et à la diffusion de documents scientifiques de niveau recherche, publiés ou non, émanant des établissements d'enseignement et de recherche français ou étrangers, des laboratoires publics ou privés. 


\title{
Ceramic panel heating under impinging methane-air premixed flame jets
}

\author{
M. Jarray, K. Chetehouna*, N. Gascoin, F. Bey \\ INSA Centre Val de Loire - Campus de Bourges, 88 boulevard Lahitolle - CS 60013 - 18022 \\ Bourges, France \\ * Corresponding author: \\ Dr. Khaled Chetehouna-E-mail: khaled.chetehouna@insa-cvl.fr - Phone: +33 248484065
}

\begin{abstract}
Due to the ever wider use of composite materials within aerospace applications, fireproof tests get recently an increased attention. Numerical simulation is expected in the coming years to accompany engineers in their design work to increase the chance of success in the fireproof certification tests. The current research focuses on the numerical investigation of a premixed methane-air flame impinging normal to a flat composite panel. The effects of the exit burner geometry, of the Reynolds number (jet speed) and of the distance between the nozzle and the plate have been investigated. The accuracy and suitability of different turbulence models are discussed. The numerical results are validated with available experimental data. CFD calculations reproduce within $5 \%$ the so-called heat transfer efficiency where the realizable $k-\varepsilon$ turbulence model demonstrates to be the best. The agreement to the experimental data is maximum (in the following order of importance): i) near the centre of the jet impingement, ii) for higher Reynolds number, iii) for higher distance between the panel and the flame. The Reynolds number increase conducts to an increase of the total heat transfer between the flame and the panel. This is related to the Nusselt number which presents higher value (over 20) in the regions for which the predictiveness of the calculation is found to be better. Efficient modelling parameters are found to reproduce an experimental flame that will serve later in fireproof test simulations.
\end{abstract}

Keywords: Fireproof burner, Numerical modeling, Impinging flame jet, Heattransfer, Fluid flow, CFD 


\section{Nomenclature}
A Area, $\left(\mathrm{m}^{2}\right)$
$C_{2 \varepsilon}, C_{1 \varepsilon} \quad \mathrm{k}-\varepsilon$ model constants
$g \quad$ Gravitational acceleration, $\left(\mathrm{m} . \mathrm{s}^{-2}\right)$
$G_{k} \quad$ Production of kinetic energy
$\mathrm{K}$ Thermal conductivity, $\left(\mathrm{W} \cdot \mathrm{m}^{-1} \cdot \mathrm{K}^{-1}\right)$
$k \quad$ Turbulence kinetic energy, $\left(\mathrm{J} \mathrm{kg}^{-1}\right)$

$\mathrm{Nu} \quad$ Nusselt number

$\mathrm{P} \quad$ Pressure, $(\mathrm{Pa})$

q" Heat flux, (W.m²)

Re Reynolds number

$\mathrm{Su} \quad$ Burning velocity $(\mathrm{m} / \mathrm{s})$

$\mathrm{t} \quad$ Time, $(\mathrm{s})$

$\mathrm{T} \quad$ Temperature, $(\mathrm{K})$

$T_{w} \quad$ Temperature at the wall, $(\mathrm{K})$

$T_{f} \quad$ Temperature of the flame (K)

$\mathrm{u} \quad$ Velocity of the fluid, $\left(\mathrm{m} . \mathrm{s}^{-1}\right)$ 
X Mole fraction

Y Mass fraction

$\mathrm{z} \quad$ Burner tip to target plate distance, (m)

$\mathrm{Z} \quad$ quartz plate thickness/depth, (m)

\section{Greek Letters}

$\alpha \quad$ Thermal diffusivity, $\left(\mathrm{m} . \mathrm{s}^{-2}\right)$

$\beta \quad$ Radial velocity gradient, $\left(\mathrm{s}^{-1}\right)$

$\gamma \quad$ Heat capacity ratio

$\Phi \quad$ Equivalence ratio

$\eta \quad$ Effectiveness

$\varepsilon \quad$ Energy Dissipation Rate, $\left(\mathrm{J} \cdot \mathrm{kg}^{-1} \cdot \mathrm{s}^{-1}\right)$

$\delta_{i j} \quad$ Kronecker symbol

$\rho \quad$ Fluid density, $\left(\mathrm{kg} . \mathrm{m}^{-3}\right)$

$\sigma_{k} \quad$ Turbulent Prandtl numbers for $\mathrm{k}$

$\sigma_{\varepsilon} \quad$ Turbulent Prandtl numbers for $\varepsilon$

$\mu \quad$ Dynamic viscosity, $\left(N s / m^{2}\right)$

$\mu_{t} \quad$ Eddy viscosity, $\left(\mathrm{m}^{2} \cdot \mathrm{s}^{-1}\right)$ 
$v \quad$ Kinematic viscosity, $\left(\mathrm{m}^{2} / \mathrm{s}\right)$

$\tau_{w} \quad$ Wall shear stress, $(\mathrm{Pa})$

$\overline{\Omega_{\imath \jmath}} \quad$ Mean rate of rotation tensor $\left(s^{-1}\right)$

$\omega_{k} \quad$ Angular velocity, $\left(\mathrm{m} . \mathrm{s}^{-1}\right)$

Subscripts/superscripts

aw adiabatic wall

f flame

FJ flame jet

i initial

j component of the mixture

m mixture

w wall

\section{Introduction}

Heat transfer due to flame jet impingement is a very important process in industry and it is used for many applications like melting scrap metal, shaping glass, brazing, welding, etc. A lot of research has been carried out in this area, both experimentally and numerically. Most of existing studies on impingement flame jets were concentrated on circular jet utilizing methane or natural gas [1-7]. Examples of experiments quantifying the heat-transfer characteristics of impinging flame jets can be found in references [812]. One of the applications that encounter emerging interest and that could take a strong benefit from numerical simulation is related to fireproof certification tests which are imposed by Federal Aviation Agency (FAA) and its European equivalent (EASA). 
Indeed, the composite panels that form the current planes must be fireproofed and experimental tests show rapid cost increase. Thus, numerical simulation could be a way to investigate panel behavior under fire conditions in order to facilitate related engineering work. To do so, many numerical parameters must be carefully managed in order to ensure the reliability of the calculations.

According to the studies of Dong et al. [13] the premixed butane-air laminar flame jet impingement heat transfer was dependent on Reynolds number, on equivalence ratio of the air/fuel jet, and on configurations of the air-fuel nozzle and of the impingement plate. Chander and Ray [14] presented a very comprehensive and informative review on impingement heat transfer, where flame shape, stabilization and burner geometries are considered. Kwok et al. [15] suggested the importance in matching the flame length with the nozzle-to-plate distance to achieve the best heat transfer performance.

Hsieh and Lin [16] have explored the stability of a methane flame jet impinging normally to a wall. They stated that the flame is relatively stable at lower inlet velocity or lower burner to plate distance.

Hindasageri et al. [17] studied heat flux distribution for premixed methane-air flame jet for Reynolds number varying from 600 to 1400 at an equivalence ratio of 1 for nozzle tip-target plate distance varying from 2 to 4 . The temperature distribution of the quartz plate is recorded using a technique based on infrared thermography where the back side and flame side heat flux are compared. These authors stated that the back side measurement would enable capturing thermal images of the impingement plate without loss of aspect ratio, which is the case for flame side measurement, due to obstruction of image by the burner tube. It should be noted that this obstruction can be avoided using numerical approaches. 
The aim of this work is to explore the possibility of predicting, numerically, the thermal behavior of a test panel, impinged by a methane-air premixed flame jet. The results of the calculations have been compared to the experimental data of Hindasageri et al. [17].

\section{Material and Methods}

\subsection{Experimental data of Hindasageri et al.}

Hindasageri et al. reported the spatial distribution of heat flux for $1.1 \mathrm{~mm}, 3 \mathrm{~mm}$ and $5 \mathrm{~mm}$ thick quartz plate, and for a varying Reynolds number, nozzle-burner tip distance and equivalence ratio, for square, circular and rectangular burners. The radial distribution of Nusselt number $(\mathrm{Nu})$ and of effectiveness $(\eta)$ is presented. Perfect circular symmetric heat flux distribution patterns were observed by Hindasageri et al. [17] for circular flame jet issuing from the burners of diameter $10 \mathrm{~mm}$ and $8.7 \mathrm{~mm}$. For the burner of diameter $10 \mathrm{~mm}$ at $\mathrm{Re}=1000$, the heat flux decreases with the increase in $\mathrm{z} / \mathrm{d}$ from 2 to 4 . For further increase in $\mathrm{z} / \mathrm{d}$ from 4 to 6 , the change in heat flux is negligible. These outcomes are in agreement with the observations reported by Grinstein and De Vore [18] and Miller et al. [19].

\subsection{Physical and numerical modeling}

The ANSYS Fluent 14 code [20] was used to solve the compressible Navier-Stokes equations in transient conditions. The pressure-velocity coupling was done using the SIMPLE scheme.

\subsubsection{Meshing}


The quality of a CFD solution is highly dependent on the quality of the mesh. Therefore, it is necessary that the grid is of high quality before proceeding to the next step. The grid structure must be fine enough where strong gradients of the variables are expected. In our study a non-uniform meshes is used with hexahedral and quadrilateral elements, more nodes accumulated around the reaction zone. A grid independence analysis was conducted using five meshes of varying cell number. Each mesh was processed using the enhanced wall treatment, with same boundary condition and a convergence of residual error set to $10^{-4}$. The mesh of 124248 nodes and 654742 elements was generated and adopted for circular burner and a mesh of 122295 nodes 644527 elements for square burner (Figure 1). By examination of different cell sizes of this mesh, no further significant change was found for finer cells; this suggests that the grid independence has been achieved. An example of test configuration is provided for illustrative purpose (Figure 2).

\subsubsection{Computational domain and conditions}

The boundary conditions are as follows. At the inlet, a fixed velocity profile is used. The wall boundary is set as no-slip condition wall by default. At the bottom part, the burnt gases flow away through pressure-outlet boundaries. The adiabatic flame temperature is taken at $2200 \mathrm{~K}$ and the ambient temperature at $300 \mathrm{~K}$. The $3 \mathrm{~mm}$ thick quartz is used.

The impingement plate is made of quartz whose size is $150 \mathrm{~mm} \times 150 \mathrm{~mm}$. The emissivity of the quartz plate reported in the literature is 0.93 [21]. The thermal conductivity $k$ and thermal diffusivity $\alpha$ of the quartz plate is computed at varying temperatures $(\mathrm{T}(\mathrm{k}))$ as per Eqs. (1)- (2)

$k=0.0015 T+0.8956$ 
$\alpha=\left(9.10^{-9} T^{2}-1 \cdot 10^{-5} T+0.0108\right) \cdot 10^{-4}$

Different numerical models were tested and a comparative analysis was carried out. The objective was to comply as much as possible with the experimental test set-up. Once this process had been finalized, it was possible to present some of the results and compare it to the experimental data. In addition the mixture of air-methane is prescribed in FLUENT. For the turbulent flame speed, the Zimont model is used [22]. It is a premixed combustion model based on the prediction the turbulent flame speed. It takes into account methane concentration, temperature, and molecular diffusion properties, as well as the detailed chemical kinetics and the influence of large eddies and small eddies on flame front wrinkling and stretching.

The solution is declared converged if the residuals of the continuity, RANS and turbulence equations are below $10^{-4}$ of their original values. The adiabatic wall temperature is estimated during the post-processing of the results using a transient thermal solver (Ansys workbench) that has been coupled with the CFD results.

For comparison purpose, simulations were conducted with the same dimensions and operating conditions as those of the experimental study of Hindasageri et al. [17]. The heat flux distribution is studied for burner tubes of circular shape $(\mathrm{d}=10 \mathrm{~mm})$ and square shape (width=10 mm). Distance between burner exit and plate is represented by a nondimensional ratio $(\mathrm{z} / \mathrm{d})$; it is varied from 2 to 6 . The length to diameter ratio $(1 / \mathrm{d})$ of all tube burners are maintained as 50. Three different Reynolds numbers of 600, 1000 and 1400 were considered. Methane-air premixed flame jet of Reynolds number varying from 600 to 1400 and an equivalence ratio of $\Phi=1$ is considered. The mixture Reynolds number $(\mathrm{Re})$ is calculated from Eq. (1). 
$R e=\frac{\rho_{m} u_{m} d}{\mu_{m}}$

Where $\mu_{m}=\frac{\sum \mu_{j} X_{j} \sqrt{M_{j}}}{\sum X_{j} \sqrt{M_{j}}}$ and $\rho_{m}=\sum Y_{j} \rho_{j}$

The effectiveness for the flame impingement process, and the Nusselt number are given by Eq.(4) and (5), as defined in [23].

$$
\eta=\frac{T_{a w}-T_{\infty}}{T_{f}-T_{\infty}}
$$

$N u=\frac{h d}{k}$

\subsubsection{Governing equations}

The flow field is determined by the celebrated Navier-Stokes equations:

Mass equation

$$
\frac{\partial \rho}{\partial t}+\operatorname{div}(\rho \vec{u})=0
$$

For an incompressible flow $\frac{\partial \rho}{\partial t}=0$

$$
\frac{\partial U_{i}}{\partial x_{j}}=0
$$

Momentum equation

$$
\frac{\partial U_{i}}{\partial t}+U_{j} \frac{\partial \rho U_{i}}{\partial x_{j}}=g_{i}-\frac{1}{\rho} \frac{\partial P}{\partial x_{i}}+\frac{\partial}{\partial x_{j}}\left(2 \mu S_{i j}-\rho \overline{u_{\imath}^{\prime} u_{j}^{\prime}}\right)
$$

Energy equation

$$
\frac{\partial T}{\partial t}+u_{j} \frac{\partial T}{\partial x_{j}}=\frac{\mathrm{k}}{\rho \mathrm{C}_{\mathrm{p}}}\left(\frac{\partial^{2} \mathrm{~T}}{\partial x_{j}}\right) .
$$


Where $\mathrm{t}$ is time; $u_{i}(\mathrm{i}=1,2,3)$ are the velocity components, $\vec{g}$ is the gravitational acceleration vector, $\rho$ is fluid density, $p$ is pressure, $\mathrm{T}$ is the Temperature, and $\tau_{i j}$ the viscous stress tensor, $S_{i j}=\frac{1}{2}\left(\frac{\partial U_{i}}{\partial x_{j}}+\frac{\partial U_{j}}{\partial x_{i}}\right)$, the rate of strain tensor $\tau_{i j}=\rho \overline{u^{\prime}{ }_{\imath}^{\prime}{ }_{j}^{\prime}}$ representing the reynolds stress tensor.

The Reynolds decomposition separates a velocity into its temporal mean and fluctuating components

$$
u_{i}=\bar{u}_{i}+u_{i}^{\prime}, p_{i}=\bar{p}_{i}+p_{i}^{\prime}
$$

where $\bar{u}_{i}$ is a varying mean fields and $u_{i}^{\prime}$ a rapidly varying turbulent components

$$
\bar{u}_{i}=\frac{1}{T} \int_{0}^{T} u\left(x_{i}, t\right) d t
$$

Reynolds operator can be thought of as the integration operator, thus we can apply it as follows:

$$
\overline{\bar{f}}=\bar{f} \text { so } \overline{f^{\prime}}=0 \& \frac{\overline{\partial f}}{\partial t}=\frac{d \partial}{\partial t}
$$

Where $\mathrm{f}$ denotes a scalar such as pressure or a vector such as velocity. For unsteady flow $\bar{u}_{i}$ may be a slow function of time.

Substituting $u_{i}=\bar{u}_{i}+u_{i}^{\prime}, p_{i}=\bar{p}_{i}+p_{i}^{\prime}$ into equation (8), we obtain

$$
\begin{aligned}
& \frac{\partial u_{i}}{\partial x_{i}}=\frac{\partial}{\partial x_{i}}\left(\bar{u}_{\iota}+u_{i}^{\prime}\right)=0 \\
& \overline{\frac{\partial\left(\overline{u_{\imath}}+u_{i_{0}}\right)}{\partial t}}+\frac{\overline{\partial\left(\overline{u_{\imath}}+u_{i_{0}}\right)\left(\overline{u_{\imath}}+u_{i_{0}}\right)}}{\partial x_{j}}=\overline{g_{i}}-\frac{\partial \bar{P}}{\rho \partial x_{j}}+\overline{\frac{\partial}{\rho \partial x_{j}}\left(\mu \frac{\partial \overline{u_{\imath}}+u_{i_{0}}}{\partial x_{j}}\right)}
\end{aligned}
$$

So

$$
\frac{\partial \overline{u_{l}}}{\partial x_{i}}=0
$$




$$
\frac{\partial \overline{u_{i}}}{\partial t}+\frac{\partial \overline{u_{i} u_{j}}}{\partial x_{j}}=g_{i}-\frac{\partial \bar{p}}{\rho \partial x_{j}}+\frac{\partial}{\partial x_{j}}\left(v\left(\frac{\partial \overline{u_{\imath}}}{\partial x_{j}}+\frac{\partial \overline{u_{j}}}{\partial x_{i}}\right)-\overline{u_{i}^{\prime} u_{j}^{\prime}}\right)
$$

Where $-\overline{u_{i}^{\prime} u_{j}^{\prime}}$ are the Reynolds stress tensor.

\subsubsection{Turbulence modelling}

The closure of the Navier-Stokes equation is performed with the help of a turbulence model. Many models are available in this context (e.g. Speziale, 1987) [24]. However, the classic model is that due to Launder et al. (1975) [25] who wrote a two-equation model for the transport of turbulent kinetic energy and turbulence dissipation from which the Reynolds stresses could be derived. The Reynolds-decomposition approach is generally adopted for practical engineering calculations, and models such as the k$\varepsilon$ model and its variants, $\mathrm{k}-\omega$ and the DES are typically used. The interested reader may find the details of these models in the appendix, or in [27-35]. The suitability of a turbulence model to provide accurate predictions for a given case varies greatly; depending on the geometry, mesh and on the value of the local Reynolds number. It is therefore not possible to determine beforehand which turbulence model is best suited for a given study. The simulations have therefore been carried out with several turbulence models, ie. the $\mathrm{k}-\varepsilon$ standard, $\mathrm{k}-\varepsilon$ realizable , $\mathrm{k}-\varepsilon \mathrm{RNG}, \mathrm{k}-\omega$, and DES models. The obtained results have then been compared to the experimental reference data of of Hindasageri et al.

\section{Results and discussions}

The accuracy of available turbulence models was evaluated on both circular and square burners for all ranges of Reynolds number and of $\mathrm{z} / \mathrm{d}$ ratio (see Figure 3). From Figure 3, the k- $\varepsilon$ RNG and realizable k- $\varepsilon$ models demonstrate a good agreement with 
the experimental results of Hindasageri et al with a slight advantage to the latter. On the opposite, the worst turbulence model for modelling the premixed methane-air flame impinging normal to a flat is the $\mathrm{k}-\omega$ model, which yields a markedly overestimated value of the effectiveness along the length of the plate especially for low burner to plate distance. The results provided by the k- $\varepsilon$ RNG Model are slightly better; while the DES model provides as well satisfactory results. For the case of the square burner $\mathrm{z} / \mathrm{d}=6$; Fig. 3 does not show a clear superiority of the realizable k- $\varepsilon$ turbulence model, but in the main test cases, it can be seen that there is a better agreement between the realizable k- $\varepsilon$ model results and experimental data, Furthermore the RNG k- $\varepsilon$ and DES models tend to over-predict the effectiveness $\eta$ at the stagnation point. It is also noticeable that the maximum Nusselt number and effectiveness at the stagnation zone for the square burner are around $5 \%$ higher than those of the circular burner for $\mathrm{K}$ for the DES, RNG and realizable $\mathrm{k}-\varepsilon$ model which is in agreement with the experimental results. From this analysis, it can be stated that the realizable k- $\varepsilon$ model gives very satisfactory results for the complex phenomena presented, even being a RANS two-equation model.

Considering the k- $\varepsilon$ realizable model, in complementarity to Figure 3 , the heat flux distribution of the quartz plate of thickness $3 \mathrm{~mm}$ impinged by a flame jet for circular burners after $15 \mathrm{~s}$ is presented (Figure 4). In both figures, it can be seen that $\eta$ decreases almost linearly as a function of $\mathrm{r} / \mathrm{d}$ starting from the stagnation point for all different cases. For all $\mathrm{z} / \mathrm{d}, \eta$ is at a maximum at the stagnation point and then decreases along the plate. It was noticed that a small increase of effectiveness value is perceptible for $\mathrm{z} / \mathrm{d}=4$, where the impingement distance is too high and where the Reynolds number is too small to produce a clear effect of heat exchange. Furthermore, the heat flux intensity in the plate decreases when the $\mathrm{z} / \mathrm{d}$ ratio is increased from 2 to 6 (Figure 4). This is in agreement with the experimental results. Particularly, it was found that for a 
small $\mathrm{z} / \mathrm{d}$ ratio the heat flux in the center jet area was relatively low. The heat transfer performance was enhanced with Re due to an increase in the premixed cone height. According to Kwok et al. [26], the heat transfer characteristics of the impinging flame jet system were enhanced with the increasing Reynolds number. So, Figure 4 is of great importance for further numerical fireproof tests because the clear impact of geometrical distances $(\mathrm{z}, \mathrm{r}$ and $\mathrm{d})$ on the effectiveness of the transfer will impose a sensitivity analysis when testing complex geometries. Indeed, the problem of repeatability which is experimentally observed could be due to a problem of accurate positioning.

According to the wall heat flux, the circular shape of the temperature distribution is strongly dependent on the burner-plate distance (Figure 5). Further away from the hot spot, an exponential decrease can be observed (that is more or less the same for all cases), since the contribution of the heat flux outside the hot spot of the plate is less than the contribution of the heat flux inside. This highlights the importance of the flame speed on the material panel and it is in good agreement with regulation and norms that impose a strict control of mass flow rate and equivalence ratio during the fireproof tests.

The variation of the Nusselt number and the effectiveness along the radial direction of the impingement plate starting from the stagnation point for different Re and jet exit-plate distances is shown in Figure 6 for circular burner. It can be seen that $\eta$ decreases almost linearly as function of $\mathrm{r} / \mathrm{d}$ starting from the stagnation point for all different cases.

It was also observed under all the conditions, for the circular burner, that the radial distribution of $\mathrm{Nu}$ has the same bell-shaped trend curves which is not the case for the square burner particularly for higher Reynolds number. For the circular burner with a plate distance higher than 2 and a Reynolds number higher than 1400, the maximum 
Nusselt number and effectiveness at the stagnation point are no longer differentiated and the effectiveness for $\mathrm{z} / \mathrm{d}=4$ and for $\mathrm{z} / \mathrm{d}=6$ are nearly equal.

\section{Conclusions and Perspectives}

Within the framework of fireproof tests, numerical simulation is a way of saving time and cost. However, tools must demonstrate to be reliable in the conditions that engineers will use them for predimensionning large structure panels of airplanes. A numerical study of heat transfer in a flat plate impinged by a premixed flame jet with different physical and boundary conditions based on experimental results by Hindasageri et al. has been performed. Circular burner with inlet diameters of $10 \mathrm{~mm}$ and square burner of sides $10 \mathrm{~mm}$ have been modeled. The efficiency of different RANS turbulence models was studied. It was found that the realizable k- $\varepsilon$ model gives the best overall results compared to the other models. Comparisons between the experimental and numerical results of the heat flux and effectiveness, under a wide different values of Re, burner shape and $z / d$, were made. The results clearly show that the heat flux varies slowly for large flame top-to-plate distances and increases rapidly for shorter distances, which is in agreement with the experimental results by Hindasageri et al. The sensitivity of the effectiveness parameter in the geometrical distances may explain the problem of experimental repeatability that is observed. Numerical fireproof tests could thus be more efficient than experimental tests. In addition, numerical tests confirm some key points which are found in the fireproof norms of FAA (like the strict control of flame speed and equivalence ratio). The variation of Nusselt number and the effectiveness with $R e$ for different jet exit-plate distances obtained by the present simulation agree well with the experimental results. A 
future work will now focus on a real 3-D aerospace panel to provide understanding of numerical ability under realistic test configuration.

\section{Figure captions}

Fig 1. Close-up view of the numerical meshing near the flame/panel interaction.

Fig. 2. Test configuration (Circular burner, $\mathrm{z} / \mathrm{d}=5, \mathrm{Re}=600, \mathrm{t}=5 \mathrm{~s}$ ).

Fig. 3. Turbulence models effects on effectiveness for circular (a to $c$ ) and square ( $d$ to

f) burners at different $\mathrm{z} / \mathrm{d}$ ratios (2 and 6) and Reynolds number (600 and 1400)

Fig. 4. Heat flux distribution computed with k- $\varepsilon$ turbulence model at $15 \mathrm{~s}$ for circular burner; diameter $10 \mathrm{~mm}$.

Fig. 5. Temperature distribution for circular burner at $15 \mathrm{~s}$

Fig. 6. Nusselt number and effectiveness distribution for circular burner of $\mathrm{d}=10 \mathrm{~mm}$, $\mathrm{z} / \mathrm{d}=2,4$ and 6 (Numerical results). 


\section{Circular Burner}

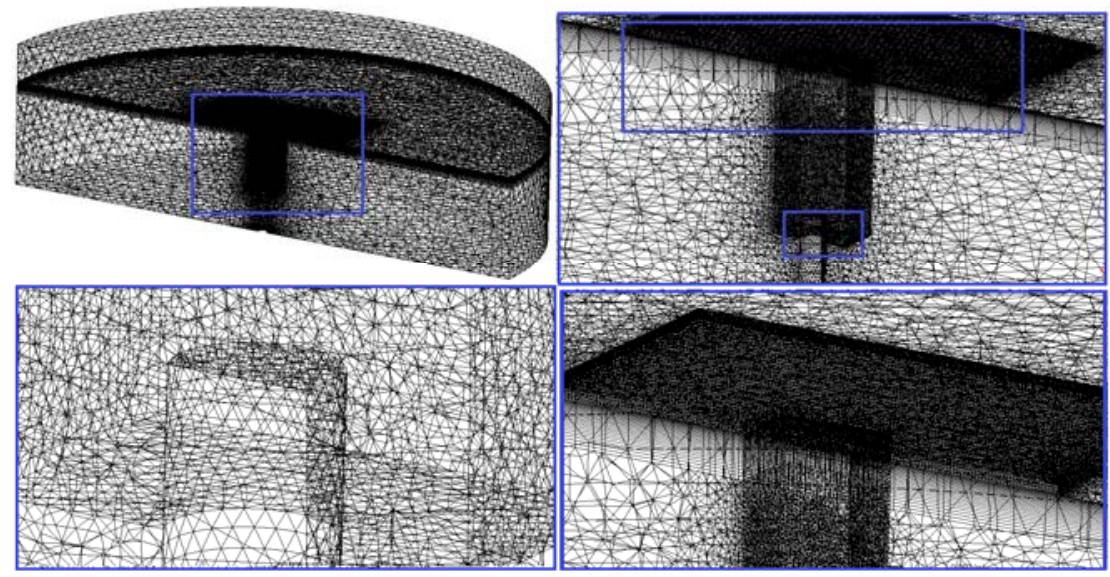

Square Burner

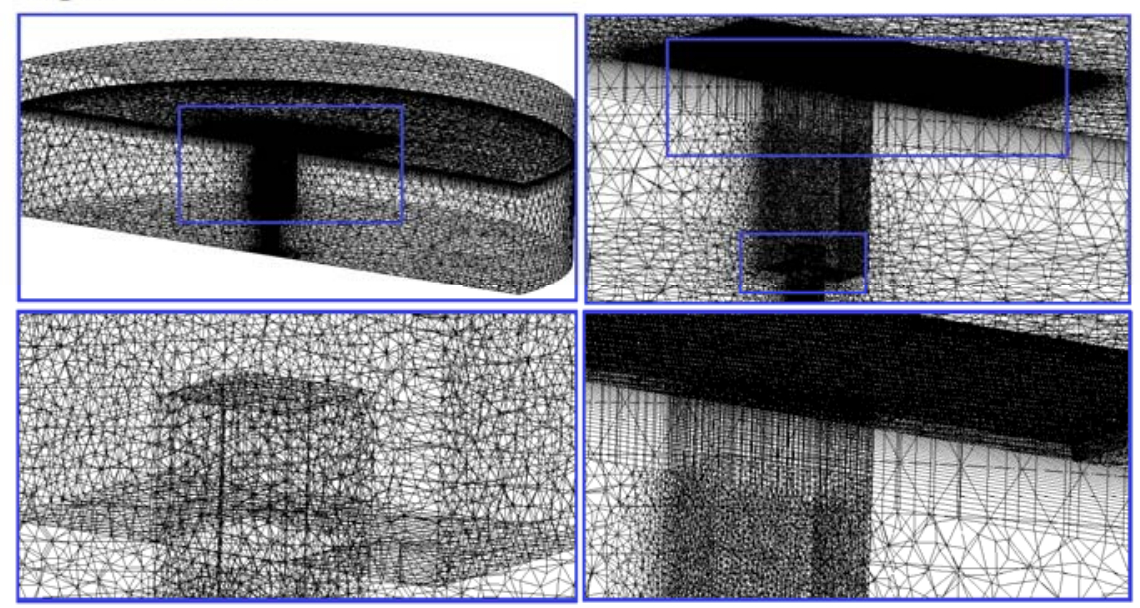

Figure 1

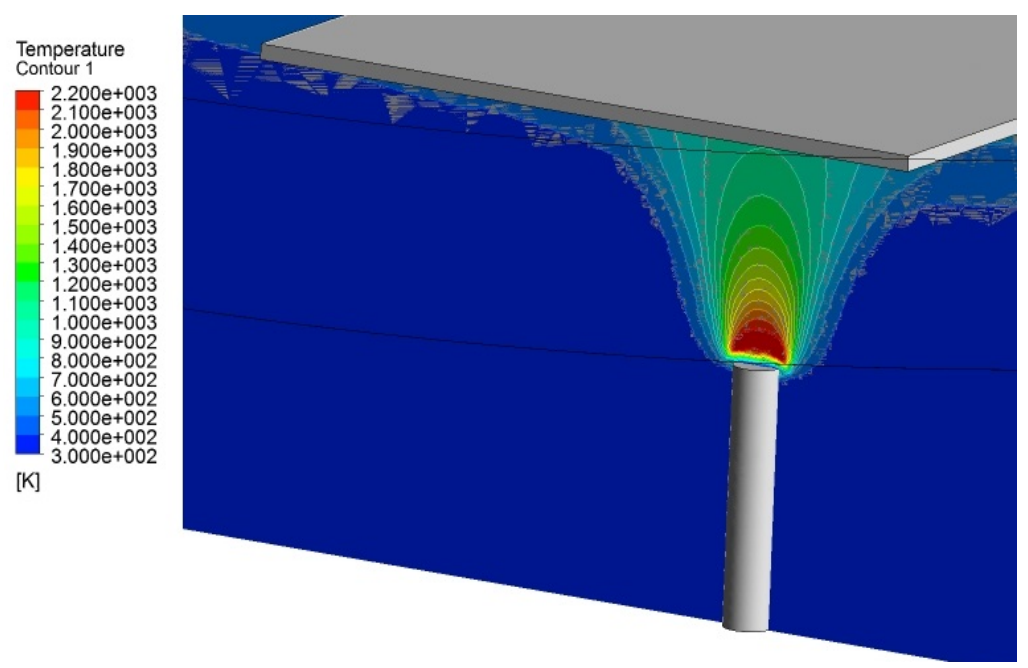

Figure 2 

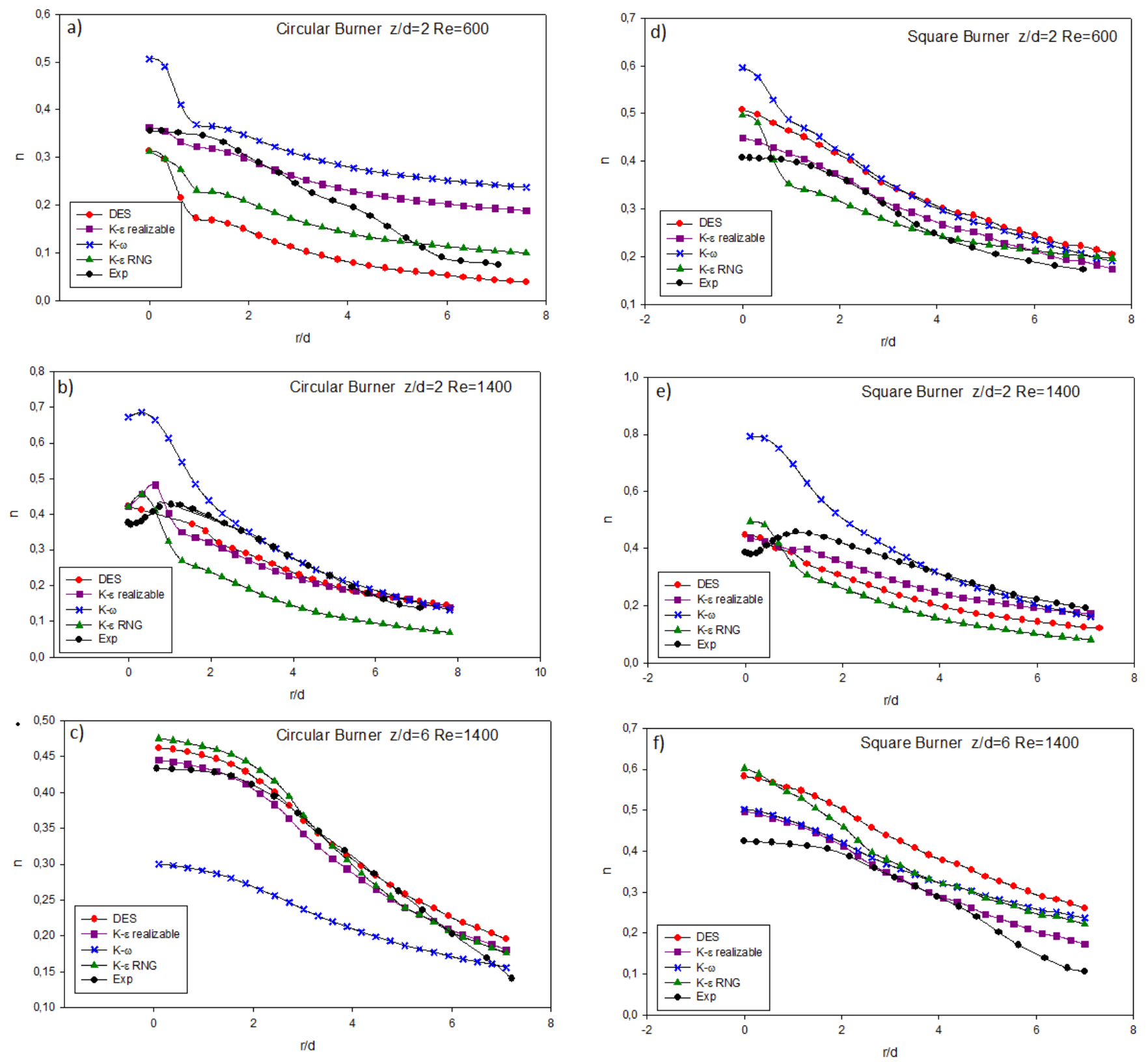

Figure 3 


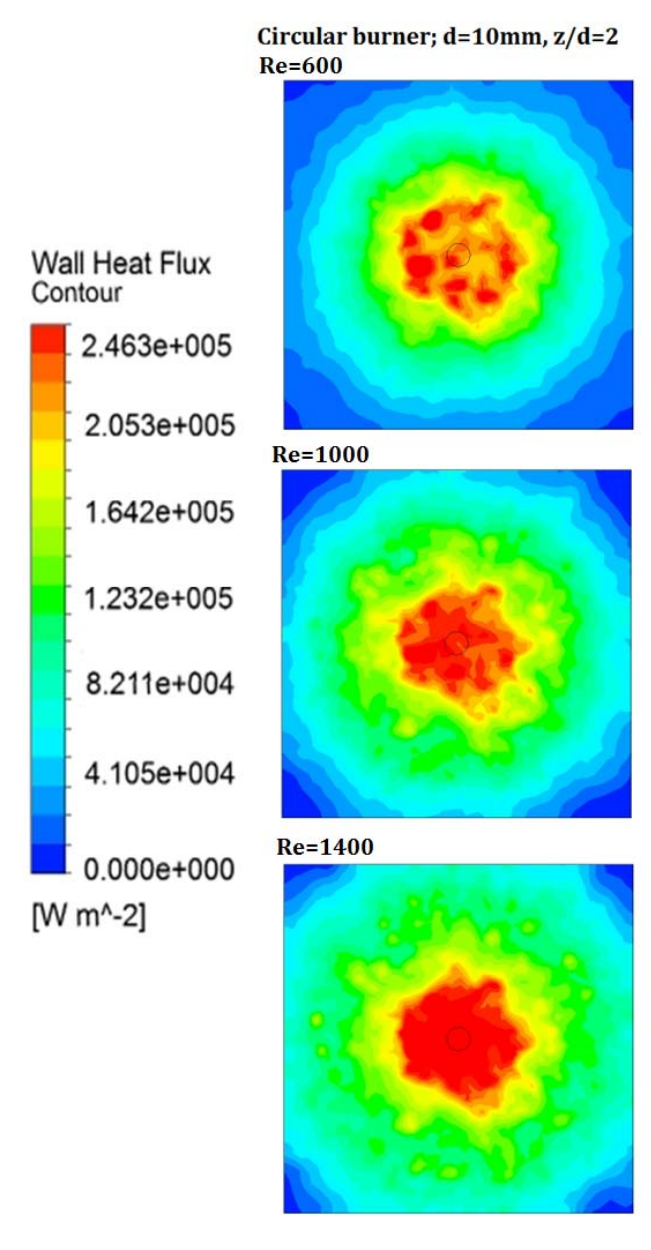

Circular burner; $d=10 \mathrm{~mm}, \mathrm{z} / \mathrm{d}=4$ $\mathrm{Re}=600$



$\mathrm{Re}=\mathbf{1 0 0 0}$

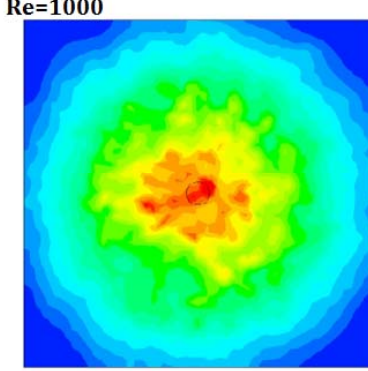

$\operatorname{Re}=1400$

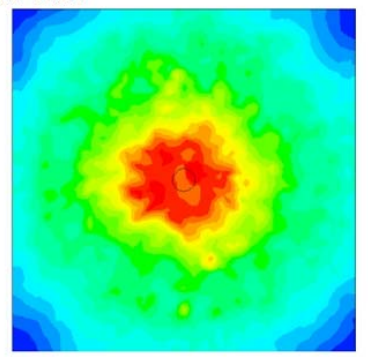

Figure 4
Circular burner; $d=10 \mathrm{~mm}, \mathrm{z} / \mathrm{d}=6$

$\mathrm{Re}=600$

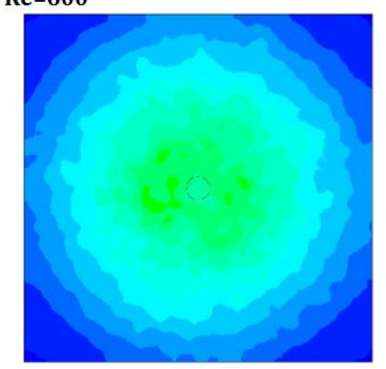

$\operatorname{Re}=1000$

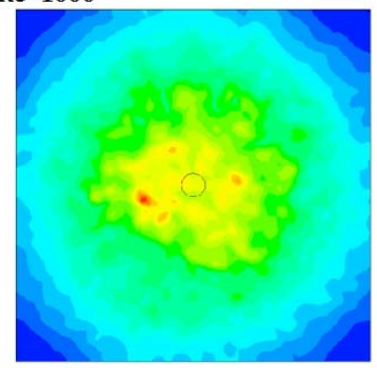

$\operatorname{Re}=1400$

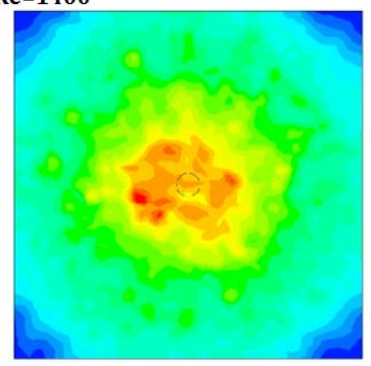




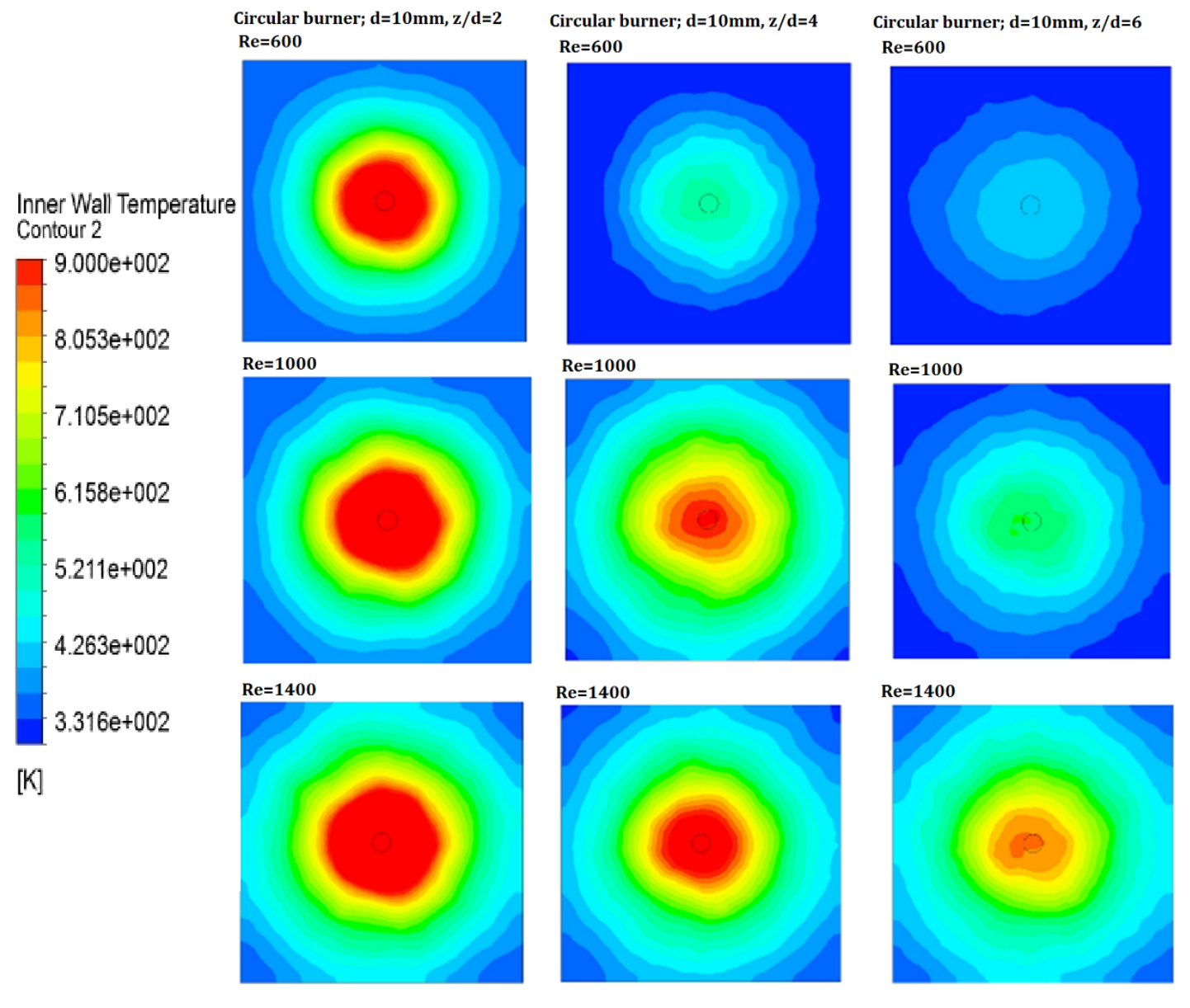

Figure 5 

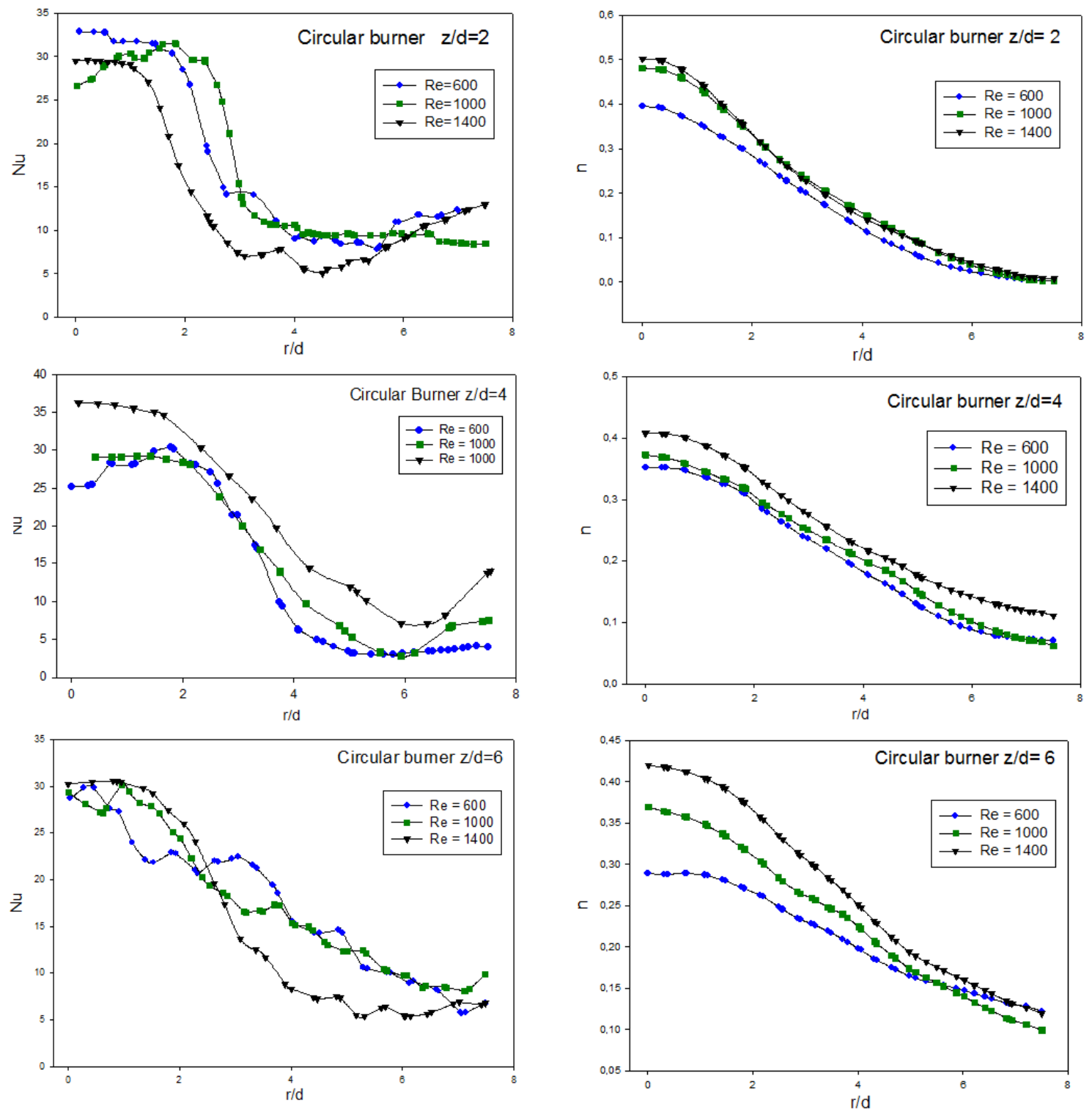

Figure 6

\section{Appendix}

\section{A.1.1.Boussinesq Approach \& Usual k-E models}

The k- $\varepsilon$ model is one of the most widely used turbulence models as it provides robustness, economy and reasonable accuracy for a wide range of turbulent flows. Improvements have been made to the standard model which improves its performance. 
Two variants are available in Fluent; the RNG (renormalization group) model and the realizable model.

A common method employs the Boussinesq relationship [27] to relate the Reynolds stresses to the mean velocity gradients, so the Reynolds shear stresses is redefined with the $\mathrm{k}-\varepsilon$ model wich employs the viscosity relation

$$
-\overline{u_{i}^{\prime} u_{j}^{\prime}}=\mu_{t}\left(\frac{\partial \overline{v_{i}}}{\partial x_{j}}+\frac{\partial \overline{v_{j}}}{\partial x_{i}}\right)-\frac{2}{3} k \delta_{i j}
$$

Where $\mathrm{k}$ the turbulent kinetic energy

$$
\mathrm{k}=\frac{u_{i}^{\prime} u_{i}^{\prime}}{2}
$$

And $\mu_{t}$ The eddy viscosity

$$
\mu_{t}=C_{\mu} \frac{k^{2}}{\varepsilon}
$$

$\delta_{i j}$ The Kronecker symbol with $\mathrm{j}=3$ indicating the vertical direction,

$\varepsilon$ The dissipation rate of $\mathrm{k}$,

$C_{\mu}$ Is a model parameter which is constant for k- $\varepsilon$ standard and RNG and equal to 0.09 , but variable for the $\mathrm{k}-\varepsilon$ realzeable.

The eddy viscosity is not a fluid property but depends strongly on the state of turbulence; $\mu_{t}$ may vary significantly from one point in the flow to another and also from flow to flow.

Equations for $\mathrm{k}$ and $\varepsilon$, together with the eddy-viscosity stress-strain relationship constitute the k- $\varepsilon$ turbulence model where $\varepsilon$ is the dissipation rate of $\mathrm{k}$.

FLUENT gives the user the choice of three models from $\mathrm{k}-\varepsilon$ family

k- $\varepsilon$ standard : The standard k- $\varepsilon$ model has been the most widely used model since it was introduced by Jones and Launder [28] As a result, its strengths and weaknesses 
are well known. According to Wilcox [29] it is generally inaccurate for flows with adverse pressure gradient (and therefore also for separated flows) which would limit its applicability for river flows. Improvements have been made to the model to improve its performance. Two of these variants are available in FLUENT: the RNG k-model and the realizable k-model.

k- $\varepsilon$ RNG: it's a more recent version of the $\mathrm{k}-\varepsilon$ model has been developed by Yakhot and Orszag [30] Using techniques called renormalization group theory, they developed a new k- $\varepsilon$ model which is known as the RNG (Re-Normalisation Group) model. The main deference between the RNG and the standard k- $\varepsilon$ models is in the expression of $C_{\varepsilon 2}$, which alters the form of the dissipation term. The RNG model decreases dissipation in regions of high mean strain rates. This should make the RNG more suitable for non-equilibrium flows, such as flows with adverse pressure gradients. The effect of swirl on turbulence is included in the RNG model, enhancing accuracy for swirling flows. While the standard k- $\varepsilon$ model is a high-Reynolds-number model, the RNG theory provides an analytically-derived differential formula for effective viscosity that accounts for low-Reynolds-number effects. These features make the RNG k- $\varepsilon$ model more accurate and reliable for a wider class of flows than the standard $\mathrm{k}-\varepsilon$ model.

k- $\varepsilon$ realizable :k- $\varepsilon$ realizable model proposed in [31], the term "realizable" means that the model satisfies certain mathematical constraints on the normal stresses, consistent with the physics of turbulent flow. An improved method for calculating the turbulent viscosity is introduced in this model. Compared to the standard version of k$\varepsilon$ model, $\mathrm{k}-\varepsilon$ realizable model provides a better prediction of the boundary layers characteristics in a large pressure gradients, separated and reticulating flows. 
The standard $\mathrm{k}-\varepsilon$ model, can guarantee niether the positivity of normal Reynolds stress $\overline{u^{2}}{ }_{j}>0$ (nonrealizable) when the strain rate is large. nor the Schwartz inequality for shear stresses in large strain rates $\left(\overline{u_{l}^{\prime} u_{J}^{\prime}}\right)^{2} \leq \overline{u_{l}^{\prime 2} u_{J}^{\prime 2}}$ [32]. In fact the normal stress in $\mathrm{x}-$ direction can be calculated from

$$
u^{\prime 2}=\frac{2}{3} k-2 C_{\mu} \frac{k^{2}}{\varepsilon} \frac{\partial u}{\partial x}
$$

so for the standard $k-\varepsilon$ model, the normal stress will be negative in flow with high strain rate

$$
\frac{k}{\varepsilon} \frac{\partial u}{\partial x}>\frac{1}{3} C_{\mu}=\frac{1}{3} 0.09=3.7
$$

which is of course unrealstic.

To overcome these problems, the realizable $\mathrm{k}-\varepsilon$ model makes the eddy-viscosity coefficient, $C_{\mu}$, dependent on the mean flow and turbulence parameters.

Since the model still relatively new, it is not clear in exactly which instances the realizable k-model consistently outperforms the RNG model. However, initial studies have shown that the realizable model provides the best performance of all the k- $\varepsilon$ model versions for several validations of separated flows and flows with complex secondary flow features [33].

\section{A.1.2 Transport Equations}

The turbulence kinetic energy, $\mathrm{k}$, and its rate of dissipation, $\varepsilon$, are obtained from the following transport equations:

$$
\begin{aligned}
& \rho\left(\frac{\partial k}{\partial t}+\frac{\partial k}{\partial x_{i}}\left(k u_{i}\right)=\frac{\partial}{\partial x_{j}}\left[\left(\mu+\frac{\mu_{t}}{\sigma_{k}}\right) \frac{\partial k}{\partial x_{j}}\right]+G_{k}+G_{b}-\rho \varepsilon-Y_{M}+S_{k}\right. \\
& \rho\left(\frac{\partial \varepsilon}{\partial t}+\frac{\partial}{\partial x_{i}}\left(\varepsilon u_{i}\right)\right)=\frac{\partial}{\partial x_{j}}\left[\left(\mu+\frac{\mu_{t}}{\sigma_{\varepsilon}}\right) \frac{\partial \varepsilon}{\partial x_{j}}\right]+C_{1 \varepsilon}\left(G_{k}+C_{\varepsilon 3} G_{b}\right) \frac{\varepsilon}{k}-C_{2 \varepsilon} \rho \frac{\varepsilon^{2}}{k}+S_{\varepsilon}
\end{aligned}
$$

$C_{2 \varepsilon}$ and $C_{1 \varepsilon}$ are constants, $S_{k}$ and $S_{\varepsilon}$ are user-defined source terms. 
$\sigma_{k}, \sigma_{\varepsilon}$ are the turbulent Prandtl numbers for $\mathrm{k}$ and $\varepsilon$, respectively. It is useful for solving the heat transfer problem of turbulent boundary layer flows.

The mathematical surgery involved in closing the $\varepsilon$ equation is more drastic than the $\mathrm{k}$ equation. The closure coefficients are found through calibration with experimental data for fundamental turbulent shear flows, such as incompressible equilibrium flow past a flat plate.

$G_{k}$ Represents the generation of turbulence kinetic energy due to the mean velocity gradients this term may be defined as

$$
G_{k}=-\rho \overline{u_{\imath}^{\prime} u_{J}^{\prime}} \frac{\partial u_{i}}{\partial x_{i}}
$$

$G_{b}$ is generation of turbulent kinetic energy that arises due to buoyancy. It's given by

$$
G_{b}=\beta g_{i} \frac{\mu_{t}}{P r_{t}} \frac{\partial T}{\partial x_{i}}
$$

where $\operatorname{Pr}_{t}$ is the turbulent Prandtl number for energy, and $\beta$ thermal expansion, where

$$
\beta=-\frac{1}{\rho}\left(\frac{\partial P}{\partial T}\right)_{p}
$$

Buoyancy occurs due to a difference in indoor-to-outdoor air density resulting from temperature and moisture differences. The greater the thermal difference and the height of the structure, the greater the buoyancy force, so in Fluent when a non-zero gravity field and temperature gradient are present simultaneously, the k- $\varepsilon$ models account for the generation of $\mathrm{k}$ due to buoyancy.

$Y_{M}$ represents the fluctuating dilation in compressible turbulence that contributes to the overall dissipation rate, For high-Mach-number flows, compressibility affects turbulence through so-called "dilatation\dissipation", which is normally neglected in the modeling of incompressible flows [33] the dilatation dissipation term, $Y_{M}$, is included in the $\mathrm{k}$ equation. This term is modeled according to a proposal by Sarkar [34]

$$
Y_{M}=2 \rho \varepsilon M_{t}^{2}
$$


where $M_{t}$ is the turbulent Mach number, defined as

$$
M_{t}=\sqrt{\frac{k}{a^{2}}}
$$

where $\mathrm{a}$ is the speed of sound

$$
a=\sqrt{\gamma R T}
$$

$\gamma$ is the heat capacity ratio, the ratio of the heat capacity at constant pressure $\left(C_{p}\right)$ to heat capacity at constant volume $\left(C_{v}\right)$.

The eddy viscosity

$$
\mu_{t}=C_{\mu} \frac{k^{2}}{\varepsilon}
$$

The RNG Transport Equations has a similar form to the standard k- $\varepsilon$ model

$$
\begin{gathered}
\rho\left(\frac{\partial k}{\partial t}+\frac{\partial k}{\partial x_{i}}\left(k u_{i}\right)=\frac{\partial}{\partial x_{j}}\left[\alpha_{k} \mu_{e f f} \frac{\partial k}{\partial x_{j}}\right]+G_{k}+G_{b}-\rho \varepsilon-Y_{M}+S_{k}\right. \\
\rho\left(\frac{\partial \varepsilon}{\partial t}+\frac{\partial}{\partial x_{i}}\left(\varepsilon u_{i}\right)\right)=\frac{\partial}{\partial x_{j}}\left[\alpha_{k} \mu_{e f f} \frac{\partial \varepsilon}{\partial x_{j}}\right]+C_{1 \varepsilon}\left(G_{k}+C_{\varepsilon 3} G_{b}\right) \frac{\varepsilon}{k}-C_{2 \varepsilon} \rho \frac{\varepsilon^{2}}{k}+S_{\varepsilon}
\end{gathered}
$$

However the turbulent viscosity is modeled by the differential equation [33]

$$
d\left(\frac{\rho^{2} k}{\sqrt{\varepsilon \mu}}\right)=1.72 \frac{\hat{v}}{\sqrt{\hat{v}^{3}-1+C_{v}}} d \hat{v}
$$

where

$$
\begin{gathered}
\mu_{e f f}=\mu \cdot \hat{v} \\
C_{v} \approx 100
\end{gathered}
$$

Turbulence, in general, is affected by rotation or swirl in the mean flow. The RNG model in FLUENT provides an option to account for the effects of swirl or rotation by modifying the turbulent viscosity appropriately. The modification takes the following functional form

$$
\mu_{t}=u_{t 0} f\left(\alpha_{s}, \Omega, \frac{k}{\varepsilon}\right)
$$


Where $u_{t 0}$ is the value of turbulent viscosity calculated without the swirl modification, $\alpha_{s}$ is a swirl constant that assumes different values depending on whether the flow is swirl-dominated or only mildly swirling.

The modeled transport equations for $\mathrm{k}$ and $\varepsilon$ in the realizable $\mathrm{k}-\varepsilon$ model are

$$
\begin{gathered}
\rho\left(\frac{\partial k}{\partial t}+\frac{\partial k}{\partial x_{i}}\left(k u_{i}\right)=\frac{\partial}{\partial x_{j}}\left[\left(\mu+\frac{\mu_{t}}{\sigma_{k}}\right) \frac{\partial k}{\partial x_{j}}\right]+G_{k}+G_{b}-\rho \varepsilon-Y_{M}+S_{k}\right. \\
\rho\left(\frac{\partial \varepsilon}{\partial t}+\frac{\partial}{\partial x_{i}}\left(\varepsilon u_{i}\right)\right)=\frac{\partial}{\partial x_{j}}\left[\left(\mu+\frac{\mu_{t}}{\sigma_{\varepsilon}}\right) \frac{\partial \varepsilon}{\partial x_{j}}\right]+\rho C_{1} S_{\varepsilon}-C_{2 \varepsilon} \rho \frac{\varepsilon^{2}}{k+\sqrt{v \varepsilon}}+C_{1 \varepsilon} \frac{\varepsilon}{k} C_{3 \varepsilon} G_{b}+S_{\varepsilon}
\end{gathered}
$$

where

$$
C_{1}=\max \left[0.43, \frac{\eta}{\eta+5}\right]
$$

and

$$
\eta=S \frac{k}{\varepsilon}
$$

The difference between the realizable k- model and the standard and RNG k-models is that $C_{\mu}$ no longer constant. It is computed from [33]

$$
C_{\mu}=\frac{1}{A_{0} A_{s} \frac{k U^{*}}{\varepsilon}}
$$

where

$$
U^{*} \equiv \sqrt{S_{i j} S_{i j}+\widetilde{\Omega_{\imath \jmath}} \widetilde{\Omega_{l j}}}
$$

and

$$
\Omega_{i j}=\overline{\Omega_{\imath \jmath}}-\varepsilon_{i j} \omega_{k} \text { and } \widetilde{\Omega_{\imath \jmath}}=\Omega_{i j}-2 \varepsilon_{i j} \omega_{k}
$$

Where $\overline{\Omega_{l \jmath}}$ is the mean rate of rotation tensor viewed in a rotating reference frame with the angular velocity $\omega_{k}$. The model constants $A_{0}$ and $A_{s}$ are given by

$$
A_{0}=4.04, A_{s}=\sqrt{6} \cos \phi
$$

where 


$$
\phi=\frac{1}{3} \cos ^{-1}(\sqrt{6} \mathrm{~W}), \quad \mathrm{W}=\frac{S_{i j} S_{j k} S_{k i}}{\tilde{S}}, \quad S=\sqrt{S_{i j} S_{i j}}, S_{i j}=\frac{1}{2}\left(\frac{\partial u_{j}}{\partial x_{i}}+\frac{\partial u_{i}}{\partial x_{j}}\right)
$$

Models Constants have the following values

Table II. 1. k- $\varepsilon$ model constants.

\begin{tabular}{|c|c|c|c|c|c|c|}
\hline & $C_{\mu}$ & $C_{1 \varepsilon}$ & $C_{2}$ & $C_{3 \varepsilon}$ & $\sigma_{k}$ & $\sigma_{\varepsilon}$ \\
\hline$k$ - standard & 0.09 & 1.44 & 1.92 & 0.7 & 1 & 1.3 \\
\hline$k-\varepsilon$ RNG & 0,0845 & 1,42 & 1,68 & 0.7 & 1 & 1,39 \\
\hline$k-\varepsilon$ Réalisable & variable & 1.44 & 1.9 & 0.7 & 1 & 1.2 \\
\hline
\end{tabular}

\section{A.2.k- $\omega$ model}

Like the $\mathrm{k}-\varepsilon$ model presented in the previous section, the $\mathrm{k}-\boldsymbol{\omega}$ model is also popular and widely used. Over the years, this model has gone over many changes and improvements. The $k-\omega$ model is an empirical model due to Wilcox [29] and it's based on model transport equations for the turbulence kinetic energy $\mathrm{k}$ and the specific dissipation rate $\omega$, which can also be thought of as the ratio of $\varepsilon$ to $\mathrm{k}$.

The turbulence kinetic energy $\mathrm{k}$, and the specific dissipation rate, $\omega$, are obtained from the following transport equations:

$$
\frac{\partial}{\partial t}(\rho k)+\frac{\partial}{\partial x_{i}}\left(\rho k u_{i}\right)=\frac{\partial}{\partial x_{j}}\left(\Gamma_{k} \frac{\partial k}{\partial x_{j}}\right)+G_{k}-Y_{k}+S_{k}
$$

And

$$
\frac{\partial}{\partial t}(\rho \omega)+\frac{\partial}{\partial x_{i}}\left(\rho \omega u_{i}\right)=\frac{\partial}{\partial x_{j}}\left(\Gamma_{\omega} \frac{\partial \omega}{\partial x_{j}}\right)+G_{\omega}-Y_{\omega}+S_{\omega}
$$

$G_{k}$ represents the generation of turbulence kinetic energy due to mean velocity 
Gradients, $G_{\omega}$ represents the generation of $\omega$

$\mathrm{Y}_{k}$ et $\mathrm{Y}_{\omega}$ represent the dissipation of $\mathrm{k}$ and $\omega$ due to turbulence

$\Gamma_{k}$ et $\Gamma_{\omega}$ represent the effective diffusivity of $\mathrm{k}$ et $\omega$ respectively

where

$$
\Gamma_{k}=\mu+\frac{\mu_{t}}{\sigma_{k}} \text { and } \Gamma_{\omega}=\mu+\frac{\mu_{t}}{\sigma_{\omega}}
$$

$\sigma_{k}, \sigma_{\varepsilon}$ are the turbulent Prandtl numbers for k et $\omega$ respectively

The turbulent viscosity is expressed as follows

$$
\mu_{t}=\alpha^{*} \frac{\rho k}{\omega}
$$

The coefficient $\alpha^{*}$ damps the turbulent viscosity causing a low-Reynolds number correction. It is given by,

$$
\alpha^{*}=\alpha_{\infty}^{*}\left(\frac{\alpha_{0}^{*}+R e_{t} / R_{k}}{1+R e_{t} / R_{k}}\right)
$$

Where

$$
R e_{t}=\frac{\rho k}{u \omega} ; R_{k}=6 ; \alpha_{0}^{*}=\frac{\beta_{i}}{3} ; \beta_{i}=0.072
$$

Note that in the high-Reynolds number form of the $k-\omega$ model, $\alpha^{*}=\alpha_{\infty}^{*}=1$.

\section{Modeling the Turbulence Production $k$}

The $k$ production may be defined as

$$
G_{k}=-\rho \overline{u_{\imath}^{\prime} u_{J}^{\prime}} \frac{\partial u_{i}}{\partial x_{i}}
$$

with the Boussinesq hypothesis,

$$
G_{k}=\mu_{t} S^{2}
$$

Where $\mathrm{S}$ is the modulus of the mean rate-of-strain tensor, defined as 


$$
S=\sqrt{S_{i j} S_{i j}}
$$

Production of $\omega$

$$
G_{\omega}=\alpha \frac{\omega}{k} G_{k}
$$

The coefficient $\alpha$ is given by

$$
\alpha=\frac{\alpha_{\infty}}{\alpha^{*}}\left(\frac{\alpha_{0}+R e_{t} / R_{\omega}}{1+R e_{t} / R_{\omega}}\right)
$$

Where $R_{k}=2.95 . \alpha^{*}$

Note that in the high-Reynolds number form of the $k-\omega$ model, $\alpha=\alpha_{\infty}=1$.

\section{Modeling the dissipation of $\mathrm{k}$}

The dissipation of $\mathrm{k}$ is given by

$$
Y_{k}=\rho \beta^{*} f_{\beta^{*}} k \omega
$$

Where

$$
f_{\beta^{*}}= \begin{cases}1 & \chi_{k} \leq 0 \\ \frac{1+680 \chi_{k}^{2}}{1+400 \chi_{k}^{2}} & \chi_{k}>0\end{cases}
$$

Where

$$
\chi_{k}=\frac{1}{\omega^{3}} \frac{\partial k}{\partial x_{j}} \frac{\partial \omega}{\partial x_{j}}
$$

and

$$
\begin{gathered}
\beta^{*}=\beta_{i}^{*}\left[1+\zeta^{*} F\left(M_{t}\right)\right] \\
\beta_{i}^{*}=\beta_{\infty}^{*}\left(\frac{\frac{4}{15}+\left(R e_{t} / R_{\beta}\right)^{4}}{1+\left(R e_{t} / R_{\beta}\right)^{4}}\right) \\
\zeta^{*}=1.5 ; R_{\beta}=8 ; \beta_{\infty}^{*}=0.09
\end{gathered}
$$

\section{Dissipation of $\omega$}


The dissipation of $\omega$ is given by

$$
Y_{\omega}=\rho \beta f_{\beta} \omega^{2}
$$

Where

$$
f_{b}=\frac{1+70 \chi_{\omega}}{1+80 \chi_{\omega}} ; \chi_{\omega}=\left|\frac{\Omega_{i j} \Omega_{j k} S_{k i}}{\left(\beta_{\infty}^{*} \omega\right)^{3}}\right| ; \Omega_{i j}=\frac{1}{2}\left(\frac{\partial u_{i}}{\partial x_{j}}-\frac{\partial u_{j}}{\partial x_{i}}\right)
$$

The strain rate tensor $S_{i j}$, is defined as

$$
\begin{aligned}
& S_{i j}=\frac{1}{2}\left(\frac{\partial u_{j}}{\partial x_{i}}+\frac{\partial u_{i}}{\partial x_{j}}\right) \\
& \beta=\beta_{i}\left[1-\frac{\beta_{i}^{*}}{\beta_{i}} \zeta^{*} F\left(M_{t}\right)\right]
\end{aligned}
$$

The compressibility function, $\mathrm{F}$ is given by

$$
F\left(M_{t}\right)= \begin{cases}0 & M_{t} \leq M_{t 0} \\ M_{t}^{2}-M_{t 0}^{2} & M_{t}>M_{t 0}\end{cases}
$$

Where

$$
M_{t}^{2}=\frac{2 k}{a^{2}} \quad M_{t 0}=0.25 \quad a=\sqrt{\gamma R T}
$$

Note that, in the high-Reynolds number form of the $k-\omega \operatorname{model}, \beta_{i}^{*}=\beta_{\infty}^{*}$. In the incompressible form $\beta=\beta_{\infty}^{*}$

Model Constants

$$
\begin{aligned}
& \alpha_{\infty}^{*}=1, \alpha_{\infty}=0.52, \alpha_{0}=\frac{1}{9}, \beta_{\infty}^{*}=0.09, \beta_{i}=0.072, R_{\beta}=8 \\
& R_{k}=6, R_{\omega}=2.95, \zeta^{*}=1.5, M_{t 0}=0.25, \sigma_{k}=2.0, \sigma_{\omega}=2.0
\end{aligned}
$$

\section{A.3.Detached Eddy Simulation DES Model}


the DES model is based on the realizable $k-\omega$ model, so it's similar to the Realizable with the exception of the dissipation term in the _equation. In the DES model, the Realizable - RANS dissipation term is modified such that [ansys theory [35]:

$$
Y_{k}=\frac{\rho k^{3 / 2}}{l_{\text {des }}}
$$

Where

$$
\begin{aligned}
& l_{\text {des }}=\min \left(l_{\text {rke }}, l_{\text {les }}\right) \\
& l_{\text {rke }}=\frac{k^{3 / 2}}{\varepsilon} \\
& l_{\text {les }}=C_{\text {des }} \Delta_{\max }
\end{aligned}
$$

Where $C_{d e s}$ is a calibration constant used in the DES model and has a value of 0.61 and $\Delta_{\text {max }}$ is the maximum local grid spacing $\left(\Delta_{x}, \Delta_{y}, \Delta_{z}\right)$. The DES length $l_{\text {des }}$ is redefined such that

$$
l_{\text {des }}=l_{\text {rke }}-f_{d} \max \left(0, l_{r k e}-C_{d e s} \Delta_{\max }\right)
$$

Where $f_{d}$ is given by:

$$
f_{d}=1-\tanh \left(\left(20 r_{d}\right)^{3}\right)
$$

\section{References}

[1] A. Milson, N.A. Chigier, Studies of methane and methane-air flames impinging on a cold plate, Combust. Flame. 21 (1973) 295-305,

[2] G.K. Hargrave, M. Fairweather, J.K. Kilham, Forced convective heat transfer from premixed flames - Part 2: Impingement heat transfer, Int. J. Heat Fluid Flow. 8 (1987) 132-138.

[3] M. Fairweather, J.K. Kilham, S. Nawaz, Stagnation point heat transfer from laminar, high temperature methane flames, Int. J. Heat Fluid Flow. 5 (1984) 225-238.. 
[4] G.K. Hargrave, M. Fairweather, J.K. Kilham, Forced convective heat transfer from premixed flames - Part 1: Flame structure, Int. J. Heat Fluid Flow. 8 (1987) 5563.

[5 ] C.E. Baukal, B. Gebhart, Heat transfer from oxygen-enhanced/natural gas flames impinging normal to a plane surface, Experimental Thermal and Fluid Science. 16 (1998) 247-259.

[6 ] R. Viskanta, Heat transfer to impinging isothermal gas and flame jets, Exp. Thermal Fluid Sci. 6 (1993) 111-134.

[7] J. Sumrerng, R. Natthawut, High efficiency heat-recirculating domestic gas burners, Exp. Thermal Fluid Sci.26 (2002) 581-592.

[8] L.L. Dong, C.W. Leung, C.S. Cheung, Heat transfer of a row of three butane/air flame jets impinging on a flat plate, Int. J. Heat Mass Transfer. 46 (2003) 113125.

[9] L.L. Dong, C.W. Leung, C.S. Cheung, Heat transfer and wall pressure characteristics of a twin premixed butane/air flame jets, Int. J. Heat Mass Transfer. 47 (2004) 489-500.

[10] L.C. Kwok, C.W. Leung, C.S. Cheung, Heat transfer characteristics of an array of impinging pre-mixed slot flame jets, Int. J. Heat Mass Transfer. 48 (2005) 17271738.

[11] Z. Zhao, T.T. Wong, C.W. Leung, Impinging premixed butane/air circular laminar flame jet - influence of impingement plate on heat transfer characteristics, Int. J. Heat Mass Transfer. 47 (2004) 5021-5031.

[12] S. Chander, A. Ray, Heat transfer characteristics of three interacting flame jets impinging on flat surface, Int. J. Heat Mass Transfer. 50 (2007) 640-653.

[13] L.L. Dong, C.S. Cheung, C.W. Leung, Heat transfer from an impinging premixed butane/air slot flame jet, Int. J. Heat Mass Transfer. 45 (2002) 979-992.

[14] S. Chander and A.Ray: Flame impingement heat transfer: A review. Energy Conversion and Management. 46 (2005) 2803-2837.

[15] L.C. Kwok, C.W. Leung, C.S. Cheung, Heat transfer characteristics of an array of impinging premixed slot flame jets, Int. J. of Heat and Mass Transfer. 48 (2005) $1727-1738$.

[16] W.D. Hsieh. and T.H.Lin : Methane flame stability in a jet impinging onto a wall. Energy Conversion and Management. 46 (2005) 727-739. 
[17] V. Hindasageri, R.P. Vedula, Siddini V. Prabhu, Heat transfer distribution for impinging methane air premixed flame jets, Applied Thermal Engineering. 73 (2014) 459-471.

[18] F.F. Grinstein, C.R. DeVore, Dynamics of coherent structures and transition to turbulence in free square jets, Phys. Fluids. 8 (1996) 1237-1251.

[19] R.S. Miller, C.K. Madnia, P. Givi, Numerical simulation of non-circular jets, Comput. Fluids. 24 (1995) 1-25.

[20] Ansys Fluent Theory Guide, Release 14.0 (2011) pp 51-53,.

[21] A.E. Wald, J.W. Salisbury, Thermal infrared directional emissivity of powdered quartz, J. Geophys. Res.100 (1995) 665-675.

[22] V. Zimont, W. Polifke, M. Bettelini, and W.Weisenstein, An Efficient Computational Model for Premixed Turbulent Combustion at High Reynolds Numbers Based on a Turbulent Flame Speed Closure, J. of Gas Turbines Power. 120 (1998) 526-532.

[23] P. Kuntikana, S.V. Prabhu, Isothermal air jet and premixed flame jet impingement: Heat transfer characterisation and comparison, Int. J. of Thermal Sciences. 100 (2006) 401-415.

[24] C.G.Speziale, On nonlinear $\mathrm{K}-1$ and $\mathrm{K}-\varepsilon$ models of turbulence. Journal of Fluid Mechanics. 178 (1987) 459-475.

[25] B.E. Launder, G.J. Reece, W. Rodi, Progress in the development of a Reynoldsstress turbulence closure. J. of Fluid Mechanics. 68 (1975) 537-566.

[26] L.C. Kwok, C.W. Leung, C.S. Cheung, Heat transfer characteristics of an array of impinging pre-mixed slot flame jets, Int. J. Heat and Mass Transfer. 48 (2005) $1727-1738$.

[27] I.B. Celik, Introductory Turbulence Modeling, West Virginia University Mechanical \& Aerospace Engineering Dept, p-33-35, 1999.

[28] B.E. Launder, G.J. Reece, W. Rodi, Progress in the development of a Reynoldsstress turbulence closure. Journal of Fluid Mechanics vol 68, 537-566, 1975.

[29] D. C.Wilcox. Turbulence Modeling for CFD. DCW Industries, Inc. La Canada, California. 1998. 
[30] V.Yakhot and S. Orszag. Renormalization group analysis of turbulence: I. basic theory. J.of Scientific Computing. 1 (1986) 3-51.

[31] J.E, Bardina, P.G. Huang and T.J. Coakley. Turbulence Modeling Validation, Testing and Development NASA Technical Memorandum 110446. 1997.

[32] k. Cen, Y. Chi Y, F. Wang, Challenges of Power Engineering and Environment, Proceedings of the International Conference on Power Engineering (2007) p.1175.

[33] Ansys Fluent Theory Guide, Release 14.0 (2011), pp45-60,

[34] S.Sarkar, L.Balakrishnan, Application of a Reynolds-Stress Turbulence Model to the Compressible Shear Layer. ICASE Report 90-18NASA CR 182002. 1990.

[35] Ansys Fluent Theory Guide, Release 14.0 (2011) pp102-103, 